\title{
Analisis Kelayakan Usaha Ternak Itik Petelur Ditinjau Dari Aspek Keuangan Pada CV Aulia Tani Desa Kuok Dusun Bukit Agung Kabupaten Kampar
}

\author{
MURNAWATI ${ }^{1}$, LILI ERTI $^{2}$, TASRIL $^{3}$ \\ Universitas Lancang Kuning \\ Jln. Yos Sudarso Km 08 Rumbai Telp. (0761) 52581 Fax. (0761) 52581 \\ E-mail : murnawati@unilak.ac.id
}

\begin{abstract}
The agricultural sector has an important role in the economy in Indonesia, therefore the livestock business can be one alternative that promises the value of future profits. Investment in the field of livestock can also be interpreted investing in an activity that has a relatively long period of time in various usaha.Permasalaha in this study are: "How the feasibility of duck livestock business in terms of financial aspects of Aulia Tani village of Kampok Dusun Gunung Agung Kampar.

This study uses descriptive method with survey approach, using secondary data and primary data from respondents to the objects asked according to theproblems and objectives to be answered, and available data available in Cv Aulia Tani Village Kuok Dusun Gunung Agung Kampar.

The results of this study on the feasibility analysis of duck livestock business in review of the financial aspects of CV Aulia Tani Desa kuok hamlet agung Kampar district. the payback method of the inverse period is acceptable because the investment has been back for 3 years three months and 26 days shorter than expected, while using the Average Rate of Return (ARR) of 58.15\% Greater than the required profit of $15 \%$, Net Present Value (NPV) method, the value obtained is Rp 41.748.937-, it means its NPV is positive value> 0 by using Internal Rate Of Return (IRR) IRR value is obtained $19,48 \%$ greater than required level of profit of $15 \%$ means that the Project is acceptable from the conclusion of some of the methods used that the field investment is acceptable, or feasible to proceed or to develop
\end{abstract}

Keywords: Feasibility, Investment, Financial aspect

Peningkatan perekonomian di Indonesia sebagian besar dipengaruhi oleh petumbuhan di sektor industri dan sektor pertanian. Sektor industri dan sektor pertanian saling berkaitan sebab bahan baku dalam proses industri didapatkan dari sektor pertanian, oleh sebab itu sektor pertanian memiliki peranan penting dalam perekonomian di Indonesia, karena itu usaha peternakan dapat dijadikan salah satu alternatif yang menjanjikan nilai keuntungan di masa depan. Investasi dalam bidang peternakan dapat pula di artikan penanaman modal dalam suatu kegiatan yang memiliki jangka waktu relative panjang dalam berbagai usaha

Salah satu ternak unggas yang mulai berkembang dimasyarakat adalah ternak itik, meskipun tidak sepopuler ternak ayam, itik mulai disukai masyarakat untuk diusahakan sehingga ternak itik semakin berkembang (Marzuki 2005) Pengembangan usaha ternak itik diindonesia telah menjadi usaha yang memiliki komponen lengkap usaha ini dapat memberikan kontribusi nyata dalam pembangunan sub sector perternakan usaha peternakan ini memiliki nilai yang strategis baik dalam penyediaan daging maupun telur dalam meningkatkan pendapatan dari masyarakat.

CV Aulia tani bergerak dalam bidang perternakan yaitu ternak itik, sehingga perlu dilakukan Kajian yang mendalam mengenai usaha ternak itik, terutama mengenai apakah usaha ternak itik petelur mampu memberikan benefit 
yang layak ditinjau dari aspek keuangan bagi masyarakat (peternak) perlu dilakukan.

Berdasarkan uraian tersebut diatas peneliti tertarik untuk melihat Kelayakan Usaha Ternak Itik Petelur ditinjau dari Aspek Keuangan pada CV Aulia Tani Desa Kuok Dusun Bukit Agung Kabupaten Kampar, Untuk melihat seberapa besar manfaat yang akan diperoleh oleh Usaha tersebut, berdasarkan penjelasan-penjelasan diatas, maka dirasankanperlu untuk membahaslebih mengenai, "Analisis Kelayakan Usaha Ternak Itik Petelur di tinjau dari Aspek Keuangan pada CV Aulia Tani Desa Kuok, Dusun Bukit Agung Kabupaten Kampar “

Berdasarkan uraian latar belakang di atas, maka rumusan masalah dalam penelitian ini adalah: "Bagaimana kelayakan Usaha ternak itik petelur ditinjau dari aspek keuangan pada CV Aulia tani desa kuok Dusun Gunung Agung Kabupaten. Kampar.

Studi kelayakan merupakan gambaran tentang usaha/proyek yang akan dikerjakan dan melalui studi kelayakan mereka akan dapat mengetahui prospek perusahaan dan kemungkinankemungkinan keuntungan yang diterima. Dengan studi kelayakan mereka akan dapat mengetahui jaminan keselamatan dari modal yang ditanam dan berdasarkan studi kelayakan ini pula, mereka akan mengambil keputusan (decisionmaking) terhadap penanaman investasi.( Billy Firman 2014)

Menurut (Nitisemito dan Burhan, 2009:47) Terdapat lima tujuan mengapa sebelum suatu usaha atau proyek dijalankan perlu dilakukan studi kelayakan yaitu: Menghindari risiko, Memudahkan perencanaan, Memudahkan pelaksanaan Pekerjaan, Memudahkan pengawasan, dan memudahkan pengendalian.

Analisis Kelayakan, Kelayakan artinya penelitian yang dilakukan secara mendalam tersebut dilakukan untuk menetukan apakah usaha yang akan dijalankan akan memberikan manfaat yang lebih besar dibandingkan dengan biaya yang akan dikeluarkan. Dengan kata lain, kelayakan dapat diartikan bahwa usaha yang akan dijalankan akan memberikan keuntungan finansial dan non finansial sesuai dengan tujuan yang mereka inginkan ( Dally 2016)

Aspek Pasar dan Pemasaran Pasar dan pemasaran merupakan dua sisi yang tidak dapat dipisahkan satu sama lainnya. Pasar dan pemasaran memiliki tingkat ketergantungan yang tinggi dan saling mempengaruhi satu sama lainnya.Dengan kata lain,setiap kegiatan pasar selalu diikut ioleh pemasaran dan setiap kegiatan pemasaran adalah untuk mencari atau mencipatakan pasar(Dally 2016)

AspekTeknis, Aspek teknis atau operasi juga dikenal sebagai aspek produksi. Hal-hal yang perlu diperhatikan dalam aspek ini adalah masalah penentuan lokasi, luas produksi, tata letak (layout), penyusunan peralatan pabrik, dan proses produksinya termasuk pemilihan teknologi.Jadi, analisis dari aspek operasi adalah untuk menilai kesiapan perusahaan(Dally 2016)

Aspek Legal dan Lingkungan, Tujuan dari aspek hukum adalah untuk meneliti keabsahan, kesempurnaan dan keaslian dari dokumen-dokumen yang dimiliki.Bagi badan usaha yang akan dijalankan juga perlu dipersiapkan hal-hal yang berkaitan dengan aspek hukum seperti badan hukum perusahaan yang dipilih seperti apakah Perseroan Terbatas (PT), firma, koperasi,atau yayasan ( Dally 2016).

Aspek Sumber Daya Manusia Organisasi dapat dipandang sebagai sarana untuk mencapai tujuan.Yang membuat perusahaan hidup dan dinamis adalah karena adanya proses-proses manajemen. Agar proses-proses manajemen dapat bekerja dengan baik, maka organisasi sebagai arananya perlu dirancang. Hasil akhir dari perancangan organisasi ini yang disebut dengan struktur organisasi ( Dally 2016). 
Tujuan menganalisis aspek finansial dari analisis kelayakan usaha untuk menentukan biaya dan manfaat yan diharapkan rencana investasi melalui perhitungan dengan membandingkan pengeluaran dan pendapatan, seperti ketersediaan dana, biaya modal, kemampuan usaha untuk membayar kembali dana tersebut dalam jangka waktu yangtelah ditentukandan menilai apakah usaha akan dapat dikembangkan terus (Dally 2016).

Investasi dapat pula diartikan penanaman modal dalam suatu kegiatan yang memiliki jangka waktu relative panjang dalam berbagai usaha, penanaman modal yang ditanamkan dalam arti sempit berupa proyek tertentu baik bersifat pisik ataupun non pisik seperti proyek pendirian pabrik, jalan, jembatan, pembangunan gedung, proyek penelitian dan pengembagan (Jakfar dan kasmir 2010:8)

Menurut (kasmir dan jakfar 2009:97-105) kriteria yang dijelaskan yang bisa digunakan untuk menentukan kelayakan suatu usaha atau investasi yaitu Payback periode (PP), Average Rate of Return (ARR), Net present Value (NPV) dan Internal Rate Of Return (IRR)

\section{METODE}

Penelitian ini menggunakan metode deskriptif dengan pendekatan survey, menggunakan data sekunder dan data primer dari responden terhadap objek-objek yang ditanyakan sesuai permasalahan dan tujuan yang ingin dijawab, dan data yang ada yang tersedia di Cv Aulia Tani Desa Kuok Dusun Gunung Agung Kabupaten Kampar

Penelitian ini dilaksanakan di CV Aulia Tani yang terletak di Desa Kuok Dusun Gunung Agung Kabupaten Kampar

Untuk membantu penulis dalam penyelesaian penelitian ini jeins data yang digunakan adalah data kwalitatif dan data kwantitatif sedangkan sumber data penulis menggunakan data primer dan data sekunder dan data yang data yang diperoleh dari literature, data primer penulis peroleh dari hasil penelitian lapangan sedangkan data sekunder penulis peroleh dari laporan keuangan di CV Aulia Tani dan data pendukung lainnya

Teknik pengumpulan data penulis melakukan wawancara langsung yaitu Tanya jawab dengan pemilik yang berwenang dalam memberikan informasi data yang diperlukan, Studi kepustakaan yang tujuaanya untuk menambah wawasan dan menambah bahan literature dan yang dapat menunjang penelitian ini

Analisa data yang digunakan dalam penelitian ini adalah dengan menggunakan metode deskriptif kwantitatif yang artinya setelah data diperoleh lalu dikelompokkan , dianalisa hubunganhubungannya sehingga dapat diinterprestasikan dengan menggunakan tiori-tiori yang berhubungan sehingga dapat dijawab permasalahan yang dihadapi perusahaan tersebut.

Analisa data menggunakan beberapa metode untuk mengukur kelayakan suatu investasi yaitu a. Payback period (PP) b. Net Present Value (NPV) c. Average Rate of return (ARR) d. Internal Rate Of Retun (IRR).

\section{HASIL}

Berdasarkan tabel 5.14 dapat di ambil keputusan dengan menggunakan metode payback periode inverstasi dapat diterima karna investasi tersebut telah kembali selama 3 tahun tiga bulan 26 hari lebih pendek dari waktu yang di perkirakan, Sedangkan dengan menggunakan Average Rate of Return (ARR) senilai 58,15\% Lebih besar dari keuntungan yang disyaratkan sebesar $15 \%$, metode Net present Value (NPV) nilai yang diperoleh sebesar Rp 41.748.937-, berarti NPVnya bernilai positif yang nilainya $>0$ dengan menggunakan Internal Rate of Return (IRR)Nilai IRR diperoleh sebesar $19,48 \%$ lebih besar dari tingkat keuntungan yang disyaratkan sebesar 15 \%berarti Proyek ini dapat diterima dari kesimpulan dari beberapa metode yang digunakan bahwa investasi lapangan dapat diterima, atau layak untuk dilanjutkan atau 
untuk dikembangkan

\section{PEMBAHASAN}

Untuk melakukan perhitungan dalam studi kelayakan dapat menggunakan beberapa aspek, berbagai aspek yang dinilai yaitu aspek pasar dan pemasaran, aspek teknik dan teknokogai, aspek manajemen, aspek hukum, dan Aspek Financial, Dalam menganalisa investasi di CV Aulia tani dilihat dari asfek Finansial dengan menggunakan beberapa metode kriteria investasi yaitu : Payback Period, Average Rate of Return (ARR), Net present Value (NPV) dan Internal Rate Of Return (IRR).

Metode Payback period PP, Metode ini merupakan teknik penilaian terhadap suatu investasi dalam pengembalian investasi dengan menggunakan aliran kas masuk bersih yang diperoleh setiap tahunnya.

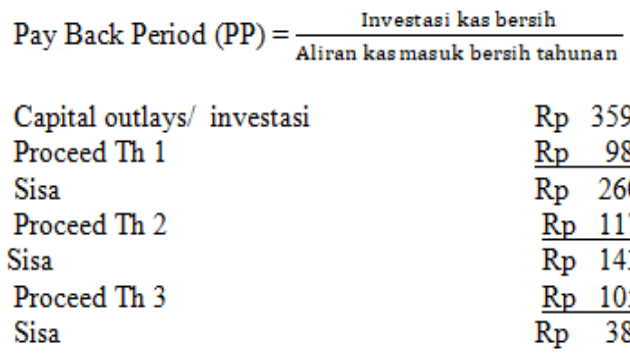

Payback Period (PP) 3 th $=$ $\frac{38.203 .150}{139.463 .500}$ $\mathrm{X} 1$ tahun $=0,273$ (dibulatkan.0,27) Pay Back Period (PP) 3,27 tahun, atau 3 tahun 03 bulan 26 hari $(0,27 \times 12=3,24=3$ Bulan $) 0,24 \times 30$ hari $=$ 7 hari

Pada tahun pertama aliran kas bersih senilai Rp 98.163.500,- , belum bisa menutupi investasi senilai Rp 359.000.000,Masih bersisa senilai Rp 260.763.500,- pada tahun ke dua aliran kas bersih senilai $\mathrm{Rp}$ 117.516.500,- masih belum bisa investasi senilai Rp 143.247.000,- belum bisa menutupi investasi tersebut, masih bersisa investasi senilai Rp 38.203.850,-, sehingga investasi baru kembali diatas Tiga tahun, jadi CV aulia tani Kabupaten Kampar investasinya kembali selama 3,27 tahun.

$$
\begin{aligned}
& \mathrm{ARR}=\frac{\text { (Rata-rata (average eaming after tax) }}{\text { Rata-rata Investasi (Average Invesment) }} \times 100 \% \\
& \mathrm{ARR}=\frac{(88136500+107516500+94043150+129463500+146421000) \cdot 5}{(359.000 .000+30.000 .000): 2} \times 100 \% \\
& \mathrm{ARR}=\frac{(113.116 .130)}{(194.500 .000)} \times 100 \%=58.15 \%
\end{aligned}
$$

Dari hasil perhitungan Average Rate of Return (ARR) Aras Futsal Pekanbaru senilai 58,15\% Lebih besar dari keuntungan yang disyaratkan sebesar $15 \%$ berarti Proyek ini dapat diterima 3.Net present Value (NPV)

Net present Value (NPV) atau nilai bersih sekarang merupakan perbandingan antara kas bersih ( $P V$ Proceed) dengan PV Investasi (Capital Out Lay) selama umur investasi, selisih antara nilai kedua PV tersebutlah yang kita kenal dengan (Net Present Value)

Net Present Value (NPV) = $\sum_{t=0}^{n} \frac{A t}{(1+k)^{t}}$, Pada tabel ditetapkan tingkat Keuntungan disyaratkan sebesar $15 \%$, sesuai dengan investasi apabila uang tidak digunakan uang itu akan kita akan simpan dibank dan akan mendapatkan keuntungan sebesar $15 \%$.

Tabel 5.13

Metode Net present Value (NPV) CV Aulia Tani 2013 s/d 2017

\begin{tabular}{|c|c|c|c|}
\hline & Proceed & Discount Faktor 15\% & $\begin{array}{r}\text { Pv Dari } \\
\text { Proceed }\end{array}$ \\
\hline I & 98.136 .500 & 0,870 & 85.378 .755 \\
\hline II & 117.516 .500 & 0,756 & 88.842 .474 \\
\hline III & 105.043 .150 & 0,657 & 69.013 .349 \\
\hline IV & 139.463 .500 & 0,572 & 79.773 .122 \\
\hline V & 156.421 .000 & 0,497 & 77.741 .237 \\
\hline & Total PV dari Proceed & & 400.748 .937 \\
\hline & Total PV dari Outlay & & 359.000 .000 \\
\hline & NPV & & 41.748 .937 \\
\hline
\end{tabular}

Dari perhitungan nilai yang diperoleh sebesar Rp 41.748.937-, berarti NPVnya bernilai positif yang nilainya $>0$ ternyata usaha ternak itik $\mathrm{CV}$ aulia tani layak untuk dikembangkan atau dilaksanakan. 
Internal Rate Of Return (IRR) merupakan alat untuk mengukur tingkat pengembalian hasil intern yatu dengan menggunakan rumus

$$
\mathrm{IRR}=i_{1}+\frac{N P V_{1}}{N P V_{1}-N P V_{2}}\left(i_{2}-i_{1}\right)
$$

$$
\text { Tabel } 5.14
$$

\begin{tabular}{l} 
Tabel 5.14 \\
\begin{tabular}{|l|c|c|c|c|c|}
\hline \multicolumn{7}{c}{ Metode ( Internal Rate Of Return (IRR tahun 2012 s/d 2016 CV Aulia tani } \\
\hline & kabupatenKampar periode 2013 s/d 2017 & $\begin{array}{c}\text { Proeed } \\
\text { Discount Faktor }\end{array}$ & $\begin{array}{c}\text { Pv Dari } \\
15 \%\end{array}$ & $\begin{array}{c}\text { Discount Faktor } \\
\text { Proceed }\end{array}$ & $\begin{array}{c}\text { Pv Dari } \\
\text { Proceed }\end{array}$ \\
\hline I & 98.136 .500 & 0,870 & 85.378 .755 & 0.833 & 81.747 .704 .5 \\
\hline II & 117.516 .500 & 0,756 & 88.842 .474 & 0.694 & 81.556 .451 \\
\hline III & 105.043 .150 & 0,657 & 69.013 .349 & 0.579 & 60.819 .983 .85 \\
\hline IV & 139.463 .500 & 0,572 & 79.773 .122 & 0.482 & 67.221 .407 \\
\hline V & 156.421 .000 & 0,497 & 77.741 .237 & 0.402 & 62.881 .242 \\
\hline & Total PV dari & & 400.748 .937 & & 354.226 .788 .4 \\
& Proceed & & & & \\
\hline & Total PV dari & & 359.000 .000 & & 359.000 .000 \\
& Outlay & & 41.748 .937 & & \\
\hline & NPV & & & & \\
\hline
\end{tabular} \\
\hline
\end{tabular}

$\mathrm{IRR}=i_{1}+\frac{N P V_{1}}{N P V_{1}-N P V_{2}}\left(i_{2}-i_{1}\right)$

IRR

$$
15+\frac{41.748 .937}{41.748 .937--4.773 .211,56} x(20-15)
$$

$I R R=15+\frac{208.744 .685}{46.522 .148,56}$

$\mathrm{IRR}=15+4,48=19,48 \%$

Hasil perhitungan dengan menggunakan internal Rate of Return, Nilai IRR diperoleh sebesar 19,48\% lebih besar

\begin{tabular}{|c|c|c|c|}
\hline \multicolumn{4}{|c|}{$\begin{array}{l}\text { Tabel } 5.15 \\
\text { Hasil penelitian di CV Aulia Tani periode 2013 s/d } 2017\end{array}$} \\
\hline No & $\begin{array}{c}\text { Metode } \\
\text { Penilaian }\end{array}$ & Hasil & Keterangan \\
\hline 1 & $\begin{array}{l}\text { Payback } \\
\text { Periode }\end{array}$ & $\begin{array}{l}3 \text { tahun } 03 \\
\text { bulan, } 26 \text { hari }\end{array}$ & $\begin{array}{l}\text { Investasi dapat dapat diterima karna lebih capat dari } \\
\text { perkiraan yaitu selama } 5 \text { tahun }\end{array}$ \\
\hline 2 & ARR & $58,15 \%$ & $\begin{array}{c}\text { Investasi dapat diterima karna hasilnya }>\text { besar dari } \\
\text { tingkat keuntungan yang disyaratkan }\end{array}$ \\
\hline 3 & NPV & Rp 41.748.937 & $\begin{array}{l}\text { Investasi dapat diterima, karna npv menghasilkan nilai } \\
\qquad \text { positif }\end{array}$ \\
\hline 4 & IRR & $19,48 \%$ & $\begin{array}{l}\text { Investasi dapat diterima kama menghasilkan > lebih } \\
\text { besar dari keuntungan yang disyaratkan sebesar } 15 \%\end{array}$ \\
\hline
\end{tabular}
dari tingkat keuntungan yang disyaratkan sebesar $15 \%$ maka IRR dapat diterima.

Berdasarkan tabel 5.14 dapat di ambil keputusan dengan menggunakan metode payback periode inverstasi dapat diterima karna investasi tersebut telah kembali selama 3 tahun tiga bulan 26 hari lebih pendek dari waktu yang di perkirakan , Sedangkan dengan menggunakan Average Rate of Return (ARR) senilai $58,15 \%$ Lebih besar dari keuntungan yang disyaratkan sebesar $15 \%$, metode Net present Value (NPV) nilai yang diperoleh sebesar Rp 41.748.937-, berarti NPV nya bernilai positif yang nilainya $>0$ dengan menggunakan Internal Rate Of Return (IRR) Nilai IRR diperoleh sebesar 19,48\% lebih besar dari tingkat keuntungan yang disyaratkan sebesar $15 \%$ berarti Proyek ini dapat diterima dari kesimpulan dari beberapa metode yang digunakan bahwa investasi lapangan dapat diterima, atau layak untuk dilanjutkan atau untuk dikembangkan.

\section{SIMPULAN}

Dari hasil penelitian yang telah di paparkan dapat diambil kesimpulan sebagai berikut:

Secara keseluruhan hasil penelitian investasi di cv Aulia tani setiap tahunnya mengalami kenaikan terhadap biaya operasional seperti biaya gaji, listrik, operasional lainnya di sebabkan semakin meningkatnya kegiatan yang dilakukan. Dan Menganlisa tentang pendapatan pada cv Aulia tani pendapatan mengalami kenaikan setiap tahunnya, dalam menganalisa didalam aspek keuangan dengan menggunakan 4 metode kelayakan investasi dengan hasil yang diperoleh sebagai berikut:

a) Metode Payback period Menunjukkkan bahwa waktu yang diperlukan untuk menutupi investasi sebesar 359.000 .000 selama 3,27 tahun, ( 3 tahun 03 bulan 26 hari )

b) Metode ARR (Average Rate of Return ) menunjukkan bahwa tingkat keuntungan yang diperoleh rata-rata sebesar 58,14\%

c) Metode Net present Value (NPV) didapat nilai yang positif sebesar Rp 41.748.937 dengan tingkat diskount faktor sebesar $15 \%$ berdasarkan criteria dapat disimpulkan investasi

p.ISSN: $2407-800 X \quad$ e.ISSN: 2541-4356 
yang ditanamkan terasebut adalah layak untuk dilaksanakan

d) Metode ( Internal Rate Of Return) perhitungan dengan IRR sebesar $19,48 \%$ tingkat keuntungan yang disyaratkan lebih besar dari tingkat discount rate yang ditentukan maka investasi yang ditanamkan dapat diterima (Layak) yang mana IRR > $15 \%$

\section{DAFTAR RUJUKAN}

Marzuki, S 2005 "Program pengentasan kemiskinan dengan usaha Peternakan itik dikabupaten magelang" Jurnal zootek Vol 35 No 1: 39-45 Januari 2015 ISSN 0852-2626

Billy Firman Manope, Paulus Kindangen, Hendra Tawas "Analisis kelayakan Usaha Komoditas Biji dan fuli Pala melalui penilaian asfek finansial pada pedagang pengumpul "Kios Chandra" dipulau Siau, Jurnal EMBA Vol 2 No 4 Desember 2014 Hal 320 - 330 ISSN $2303-1174$

Dally Darmaseptana, Alex Saleh, Dwi Kurniawan Analisis Kelayakan Usaha Pengollahan Susu sapi Murni di Kota Bandung RekaIntegraISSN:2338-5081 JurnalOnlineInstitutTeknologiNasional No 1 Vol 4 Januari 2016

BellaGladys Endoh*,A.Makalew, M. A.VManese,T. F.DLumy Analisis Rentabilitas ternak itik petelur di Desa Wolaang kecamatan Langowan timur Kabupaten Minahasa Junal Zootek ISSN 0852 - 2626 Vol 36,198 206 Januari 2016

Joicke E,Lembong, N,M Santa, A,Makaleu dan F H Willy, Analisis Break even point Usaha ternak itik pedaging madano Jurnal Zootek Vol 35 no. 1: 39 - 45 Januari 2015

Sandi rikri and kasih, Yulizar and Diah
Wenny 2016 Perencanaan Pendirian usaha ternak bebek (Bekri) Jurnal Bekri URL

http://eprint.mpd.ac.id/id/eprint/1808

Risal Rinofahdan IGNSoni Kurniawan 2016 Analisis kelayakan usaha warung burjo (studi kasus di dusun karang gayam, catur tunggal ,JKB ISSN 1979 - 861 x eISSN 2549 1555 Vol 19 no X Desember 2016

Jakfar dan kasmir (2010) Studi kelayakan bisnis, Penerbit kencana prenada media Group jakarta

KasmirdanJakfar.,(2009),StudiKelayakanB isnis,EdisiKedua,PenerbitKencanaPr enada Media Grup Jakarta

Nitisemito, Alex S,Umar burhan, Wawasan Studi kelayakan dan evaluasi Proyek, Bumi Aksara Jakarta 2009 